\title{
Hardness and Degree of Conversion of Dental Restorative Composites Based on an Organic-inorganic Hybrid
}

\author{
Sandro Aurélio de Souza Venter, Silvia Luciana Fávarob, \\ Eduardo Radovanovic ${ }^{\mathrm{b}}$ Emerson Marcelo Girotto ${ }^{\mathrm{b} *}$ \\ ${ }^{a}$ Universidade Tecnológica Federal do Paraná - UTFPR, Rua Marcílio Dias, 635, \\ CEP 86812-460, Apucarana, PR, Brazil \\ ${ }^{\mathrm{b}}$ Departamento de Química, Universidade Estadual de Maringá - UEM, Av. Colombo, 5790, \\ CEP 87020-900, Maringá, PR, Brazil
}

Received: October 29, 2012; Revised: January 14, 2013

\begin{abstract}
This paper presents a factorial design (mixture design) used to analyze the hardness and degree of monomer conversion into composites containing conventional monomers and an organic-inorganic hybrid polymer-based methacryloyloxypropyl trimethoxysilane (MEMO). For this purpose, resins (composites with $\mathrm{SiO}_{2}$ ) were formulated with the hybrid polymer (polycondensed, pMEMO), and two conventional monomers used in dentistry, bisphenol-A dimethacrylate (Bis-GMA) and triethyleneglycol dimethacrylate (TEGDMA). The resins were characterized through the degree of monomer conversion and Vickers hardness, and the pMEMO by means of FTIR and ${ }^{1} \mathrm{H}$ NMR. The results showed an increase in hardness for resins containing the hybrid material relative to the resins containing only conventional monomers. The mathematical model adjusted to the experimental data yielded an optimized formulation, which presented a higher hardness value $(48.88 \mathrm{HV})$.
\end{abstract}

Keywords: organic-inorganic hybrid, sol-gel, Vickers hardness, ORMOCER ${ }^{\circledR}$

\section{Introduction}

Composites are materials prepared by mixing two or more components at macroscopic level and formed by distinct phases. Class II hybrid polymers are homogeneous materials that have an inorganic network covalently bonded to polymerizable carbon chains, which, under appropriate conditions, produce a polymer network in the hybrid system and form an Organically Modified Ceramic $\left(\text { ORMOCER }^{\circledR}\right)^{1}$. These materials can be prepared through a sol-gel process by using liquid precursors, leading to systems with chemical and mechanical performances that are higher than those of mixtures of organic matrixes and inorganic inclusions ${ }^{2}$.

Commercial products based on hybrid polymers, such as Definite ${ }^{\circledR}$ (Degussa, Germany), demonstrating good mechanical properties, adhesion to teeth, elasticity and wear resistance in oral environment ${ }^{3}$ have been available for decades ${ }^{4,5}$. However, the non-reacted diluting monomers found in Definite ${ }^{\circledR}$ formulation may leach and cause toxic effects and tissue irritation ${ }^{6,7}$.

The mechanical hardness property is defined as the resistance of a material to permanent penetration and is intuitively related to the wear of dental restorative resins in the oral environment ${ }^{8}$. In hybrid resins, an inorganic three-dimension network is formed by polycondensation of the alkoxysilanes, producing siloxane bonds ( $\mathrm{Si}-\mathrm{O}-\mathrm{Si}$ ) as hard as those of glass, this may explain the high hardness of these materials. Studies have demonstrated that comparatively to dental restorative resins based on

*e-mail: emgirotto@uem.br conventional dimethacrylate monomers, formulations containing organic-inorganic hybrid polymers have higher hardness values?.

Pure organic-inorganic polymers are highly viscous, which makes their handling and consequently curing difficult ${ }^{10}$. However, some studies on resins using polycondensed (3-methacryloyloxypropyl)trimethoxysilane (pMEMO) in combination with diluting monomers have shown an increase in the hardness of the formulations with an increase in the amounts of diluents. This fact may be related to a more efficient reticulation with the use of diluting monomers due to the greater mobility of the chains of the hybrid materials in these mixtures.

The objective of this study was to evaluate the degree of conversion and Vickers hardness of dental restorative resins containing a hybrid polymer (pMEMO) as a component by a factorial design. The compositions were evaluated in the presence and in the absence of diluting monomers such as triethyleneglycoldimethacrylate (TEGDMA). The efficacy of production of pMEMO using the sol-gel process was also evaluated.

\section{Material and Methods}

All the reagents used in this study were acquired from Sigma-Aldrich: bisphenol A glycidyl dimethacrylate (Bis-GMA), (3-methacryloyloxypropyl)trimethoxysilane (MEMO, 98\%), and triethylene glycol dimethacrylate (TEGDMA, 95\%). Camphorquinone (CQ, 97\%) and 
2-(dimethylamino)ethylmethacrylate (DMAEMA, 99\%) were used as a photoinitiation system. Microparticulated silica (V117 1075, E-3000, $7.5 \mu \mathrm{m}$, Esstech Inc., Essington, USA) was used as the inorganic inclusion. All the materials were used as received.

\subsection{Sol-gel process}

The hydrolysis and condensation process was carried out with a molar ratio of 1:3:0.01 MEMO: $\mathrm{H}_{2} \mathrm{O}: \mathrm{HCl}$ under magnetic stirring at room temperature for $48 \mathrm{~h}$ and later heated to $60{ }^{\circ} \mathrm{C}$ for $5 \mathrm{~h}^{11}$. The solvent was removed under reduced pressure and mild heating in a rotary evaporator (Fisaton, model 802, São Paulo, Brazil) till a viscous yellow liquid was obtained.

\section{2. ${ }^{1} H N M R$}

${ }^{1} \mathrm{H}$ NMR spectra were recorded in a Varian Mercury Plus 300 model apparatus at $300.06 \mathrm{MHz}$; all samples were solubilized with a deuterated chloroform.

\subsection{Resin preparation}

Specific amounts of monomers were weighed in Petri dishes, to which the photoinitiaton system $(0.8 \%$ camphorquinone and 3.2\% DMAEMA in relation to the monomer mass) was added. Silica was weighed separately and added in small amounts to the Petri dishes. The mixtures were manually homogenized with a plastic $\left(\right.$ Teflon $\left.^{\circledR}\right)$ spatula. The compositions of the resins are presented in Table 1.

\subsection{FTIR: degree of conversion}

The degree of conversion of double aliphatic bonds for the formation of carbon chains was evaluated after irradiation of each side of the samples formed in a Teflon ${ }^{\circledR}$ mold of $2.10 \mathrm{~mm}$ thickness and $7.15 \mathrm{~mm}$ diameter for $180 \mathrm{~s}$ using a LED light curing unit (radii-cal, SDI-Ltd, Melbourne, Australia, $470 \mathrm{~nm}, 1200 \mathrm{~mW} / \mathrm{cm}^{2}$ ). The irradiated samples were left in a desiccator for $24 \mathrm{~h}$ and pulverized before pressing into $\mathrm{KBr}$ pellets for measurement of infrared spectra. The infrared spectra of the non-photopolymerized resins were acquired with the samples spread on a $\mathrm{NaCl}$ window. The measurements were made in a FTIR Bomem MB-100 Hartmann and Bomem spectrophotometer. For the calculation of the degree of conversion, the decrease in the peak of the aliphatic $\mathrm{C}=\mathrm{C}$ bond $\left(1640 \mathrm{~cm}^{-1}\right)$ was compared

Table 1. Mean degree of conversion and Vickers hardness obtained by simplex-centroid experimental design of the mixture composition.

\begin{tabular}{cccc}
\hline Treatment & Mixture* $^{*}$ & $\begin{array}{c}\text { Degree of } \\
\text { conversion }(\%)\end{array}$ & Hardness (HV) \\
\hline 1 & $(1,0,0)$ & $27.71 \pm 7.60$ & $42.94 \pm 3.89$ \\
2 & $(0,1,0)$ & $76.78 \pm 2.79$ & $26.21 \pm 1.59$ \\
3 & $(0,0,1)$ & $56.45 \pm 7.21$ & $26.74 \pm 2.61$ \\
4 & $(1 / 2,1 / 2,0)$ & $67.33 \pm 1.96$ & $47.66 \pm 3.08$ \\
5 & $(1 / 2,0,1 / 2)$ & $52.65 \pm 9.30$ & $36.53 \pm 1.02$ \\
6 & $(0,1 / 2,1 / 2)$ & $79.54 \pm 0.98$ & $31.07 \pm 1.81$ \\
7 & $(1 / 3,1 / 3,1 / 3)$ & $65.78 \pm 1.17$ & $38.84 \pm 2.79$ \\
\hline${ }^{*}\left(\%_{\text {pMEMO }}, \%_{\text {TEG }}, \%_{\text {BIS }}, x 100\right.$ in mass percentage.
\end{tabular}

to the peak of the $\mathrm{C}=\mathrm{O}$ bond stretching (internal reference band, at $1720 \mathrm{~cm}^{-1}$ ). The degree of conversion (DC) of the monomer was obtained with Equation 1, where $\mathrm{R}=$ intensity of the band at $1640 \mathrm{~cm}^{-1} /$ intensity of the band at $1720 \mathrm{~cm}^{-1}$.

$\mathrm{DC}(\%)=100 *[1-(\mathrm{R}$ polymer/R monomer $)]$

\subsection{Vickers hardness}

For the determination of Vickers hardness, the samples were prepared in a cylindrical mold, as described in 2.4. To prevent the formation of an inhibiting surface layer due to the contact of the material with oxygen from atmosphere, a transparent PVC film was used to cover the resin during photopolymerization. Hardness measurements were performed with a Vickers tester (Digital Display Low Load Vickers Hardness Tester, model HVS-5, São Paulo, Brazil) with a load of $0.3 \mathrm{~kg}$ applied for $20 \mathrm{~s}$. The measurements presented in this study are the means of six repetitions.

\section{Results and Discussion}

\subsection{FTIR characterization}

Figure 1 presents the infrared spectra of MEMO before and after (pMEMO) hydrolytic condensation. The band relative to the symmetric stretching of the $\mathrm{C}-\mathrm{H}$ bonds of the methoxy groups at $2840 \mathrm{~cm}^{-1}$ shown in plot (A) of MEMO before its hydrolysis is not observed in spectrum (B), indicating that the hydrolysis process effectively converted the methoxy groups bound to silica into $\mathrm{Si}-\mathrm{OH}$ with the release of methanol ${ }^{12}$. The appearance of a broad band in the $3500 \mathrm{~cm}^{-1}$ region in (B), assigned to the stretching of $\mathrm{O}-\mathrm{H}$ bonds, makes the hydrolysis of the mentioned methoxy groups evident. The condensation of the silanol groups for the formation of siloxane bonds $\mathrm{Si}-\mathrm{O}-\mathrm{Si}$ may be related to the stretching of these bonds, observed through a broader band in the $1120 \mathrm{~cm}^{-1}$ region ${ }^{13}$.

\section{2. ${ }^{1} H$ nuclear magnetic resonance}

Figure 2 shows the chemical shifts of the hydrogens of alkoxysilane MEMO before and after hydrolysis and

(a)

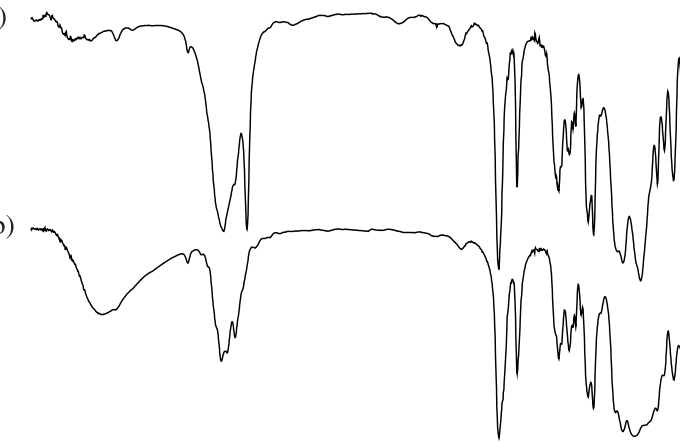

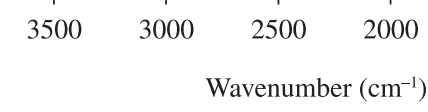

Figure 1. Infrared spectra of (a) MEMO and (b) pMEMO. 
condensation. Two characteristics stand out for the chemical shifts before and after hydrolytic condensation. First, the signal associated with the nine hydrogens of the methoxy groups of alkoxysilane at $\delta=3.55 \mathrm{ppm}$ is not observed in the spectrum of pMEMO $(\mathrm{B})^{14}$, indicating the effective reaction. The broadening of the other peaks of pMEMO hydrogens indicates a polymerization and/or an oligomerization process involving the condensation of the hydroxyl groups bound to silicon atoms and the formation of siloxane bonds ( $\mathrm{Si}-\mathrm{O}-\mathrm{Si})$, which is corroborated by the band at $1120 \mathrm{~cm}^{-1}$ in Figure 1 .

\subsection{Experimental design}

A simplex-centroid experimental design of the mixture composition was used to evaluate the effect of components pMEMO, TEGDMA and Bis-GMA on the degree of monomer conversion and Vickers hardness. This mixture design is used to analyze the relationship involved in a process that contains several variables. Simplex-centroid design is constructed to form a triangle with data points located at each corner, three midpoints on each edge, as well as a centered point. It is highly effective at demonstrating the significance related to the three primary components.

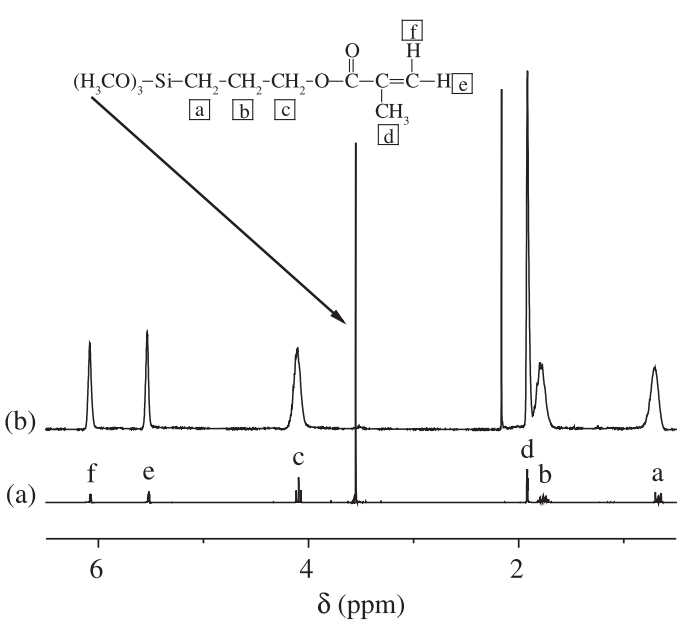

Figure 2. ${ }^{1} \mathrm{H}$ NMR spectra and peak assignment of (a) MEMO and (b) pMEMO, in $\mathrm{CDCl}_{3}$.

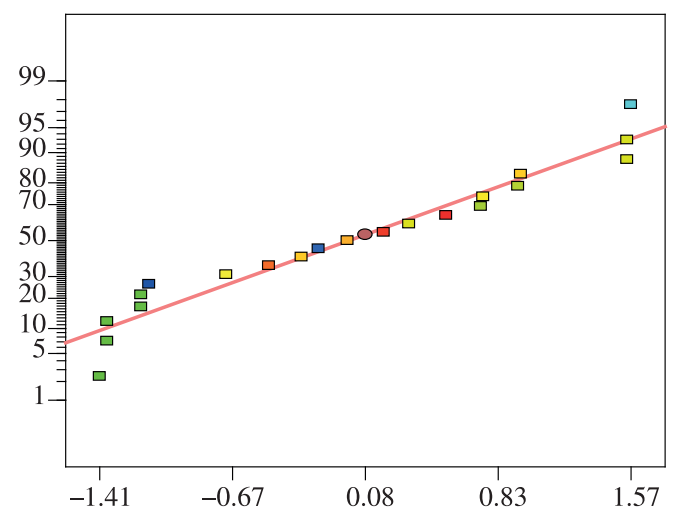

(a)
Our experimental design for the three components involved six assays and a central point in the conditions presented in Table 1. As the assays were repeated, the response variance of each assay was used to estimate the overall variance of individual responses.

The main effects of the pMEMO $\left(x_{1}\right), \operatorname{TEGDMA}\left(x_{2}\right)$ and Bis-GMA $\left(x_{3}\right)$ contents and the combination of factors on the degree of conversion and hardness were evaluated according to the design given in Table 1 using software Design Expert ${ }^{\circledR}$. The quadratic models represented by Equations 2 and 3 were obtained using simplex-centroid mixture design for the degree of conversion and hardness results, respectively.

$$
\begin{aligned}
& \mathrm{y}=\underset{( \pm 3.89)}{27.24 x_{1}}+\underset{( \pm 3.89)}{76.34 x_{2}}+\underset{( \pm 3.89)}{55.98 x_{3}}+\underset{( \pm 17.88)}{69.75} x_{1} x_{2}+\underset{( \pm 17.88)}{51.72 x_{1} x_{3}-46.49 x_{2} x_{3}}(2) \\
& \mathrm{y}=43.05 x_{1}+26.63 x_{2}+26.85 x_{3}+49.33 x_{1} x_{2} 4.37 x_{1} x_{3}+15.51 x_{2} x_{3}(3) \\
& \begin{array}{lllll}
( \pm 1.47) & ( \pm 1.47) & ( \pm 1.47) & ( \pm 6.74) & ( \pm 6.74)
\end{array}
\end{aligned}
$$

The reliability of the models proposed was evaluated by ANOVA variance analysis. The quadratic models were found to fit the experimental data well and were significant for $\mathrm{P}$ values for degree of conversion and hardness of 0.1712 and 0.3928 , respectively, showing that the lack of fit for the quadratic model is not significant. The residues analysis presented in Figure 3 shows that the residues are distributed in a random way in accordance to the ANOVA data. The models explain $86.32 \%$ of the degree of conversion and $92.71 \%$ of the hardness, relative to the total variation. In addition, according to ANOVA, the maximum values that could be explained (obtained by exclusion of pure error) are $88.09 \%$ and $99.59 \%$ for the degree of conversion and hardness, respectively. These results indicate that the quadratic models can be used to estimate the results within the interval of study. Thus, the quadratic models of Equations 2 and 3 are significant and fit the experimental values well, and therefore, they can be used for estimate purposes.

The analysis of the coefficients of the quadratic equation (Equation 2) for the degree of conversion shows that the main effect is that of the TEGDMA content $\left(76.34 x_{2}\right)$; thus, it is responsible for the high values of degree of conversion. The high degree of conversion of the resin prepared with $100 \%$ TEGDMA stands out; however, its low hardness (26.21 HV, Table 1) is an unexpected tendency for such a

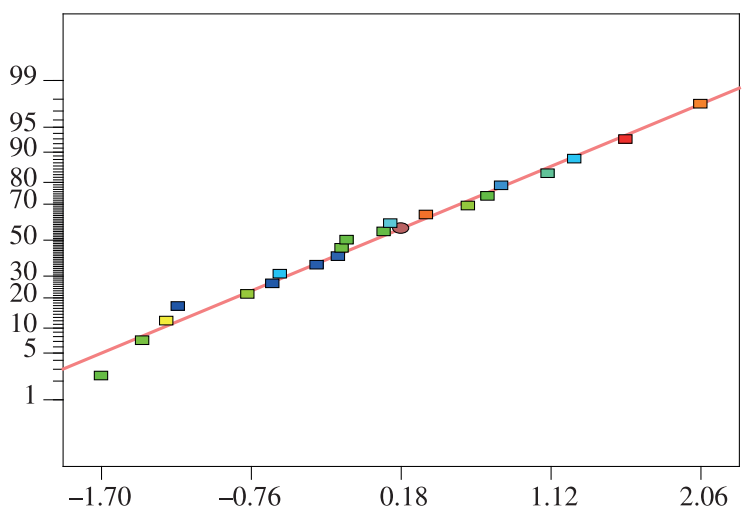

(b)

Figure 3. Normal plot of residuals for the quadratic model from the simplex-centroid design for (a) degree of conversion, (b) Vickers hardness. 
sample with high degree of conversion, since the literature proposes high hardness for composites with high degree of conversions. This fact can be assigned specifically to the use of diluting monomers such as TEGDMA. Although they afford greater mobility to the system components, they may also produce primary and secondary cyclizations. These cyclizations, which are TEGDMA intramolecular bonds, increase the degree of conversion; however, a threedimension network is not formed, which explains the low hardness of the composites prepared with excess diluents ${ }^{15}$.

The coefficient of interaction of factors $x_{1}$ and $x_{2}$ is high $\left(69.75 x_{1} x_{2}\right)$, which suggests a strong synergetic effect between components pMEMO and TEGDMA. The high viscosity of pMEMO and the known lower reactivity of methacrylate groups in hybrid systems (due to mobility restrictions) are effects that can be improved with the addition of diluting monomer TEGDMA and making the reticulation process more effective. Previous studies reported an increase in Vickers hardness of resins formed by ORMOCER ${ }^{\circledR} /$ TEGDMA with an increase in the content of the diluting monomer, which is in agreement with the results found for the current experimental design 9 .

The quadratic model (Equation 3) showed that the pMEMO content is the most significant variable, and therefore the material that has a greater pMEMO content shows greater hardness. The formation of siloxane ( $\mathrm{Si}-\mathrm{O}-\mathrm{Si}$ ) bonds in the hybrid system increases the hardness of the resins due to the rigidity of these bonds when compared to the carbon bonds of resins based on a purely organic matrix (i.e., non hybrids) such as in conventional dimethacrylate monomers. Mixture $x_{1} x_{3}$ (xpMEMO+xBis-GMA) is negligible for the fitted model because its coefficient $\left(4.37 x_{1} x_{3}\right)$ is smaller than the associated standard deviation. The region of combination of the three variables $x_{1}, x_{2}$ and $x_{3}$ is observable in the level plots (response surface) given by the mathematical models, shown in Figure 4, for the degree of conversion (A) and hardness (B).

It can be noted in Figure $4 \mathrm{a}$ that for TEGDMA concentrations close to $100 \%$, red regions, greater degree of conversions are obtained, which is expected, as previously discussed. For the hardness assay, Figure $4 b$, the best values are located close to the edge between variables $x_{1}$ (pMEMO) and $x_{2}$ (TEGDMA). However, a region that satisfies both properties simultaneously is required, that is, a region where both degree of conversion and hardness are the highest. By analyzing both response surfaces simultaneously (Figures $4 \mathrm{a}, \mathrm{b}$ ), we observe that the region which satisfies both properties lies near to the composition of about $50 \%$ of component $x_{1}$ (pMEMO) and $45 \%$ of component $x_{2}$ (TEGDMA).

To test the models fitted with Equations 2 and 3, an optimized composition containing 50.9\% pMEMO, $46.7 \%$ TEGDMA and $2.4 \%$ Bis-GMA was prepared. The degree of conversion and Vickers hardness values obtained were $72.36 \%$ and $48.88 \mathrm{HV}$, respectively. The values predicted by the model with $95 \%$ confidence were $67.53 \pm 6.76 \%$ and $46.95 \pm 2.55 \mathrm{HV}$. Therefore, as the results are within this confidence interval, it can be concluded that they are very

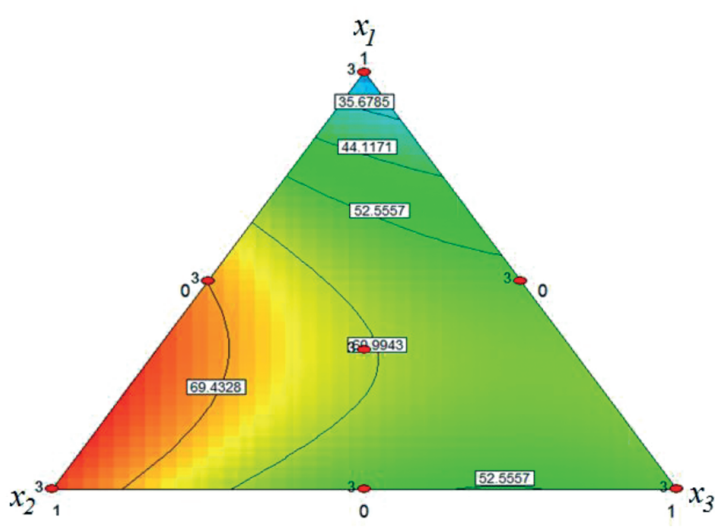

(a)

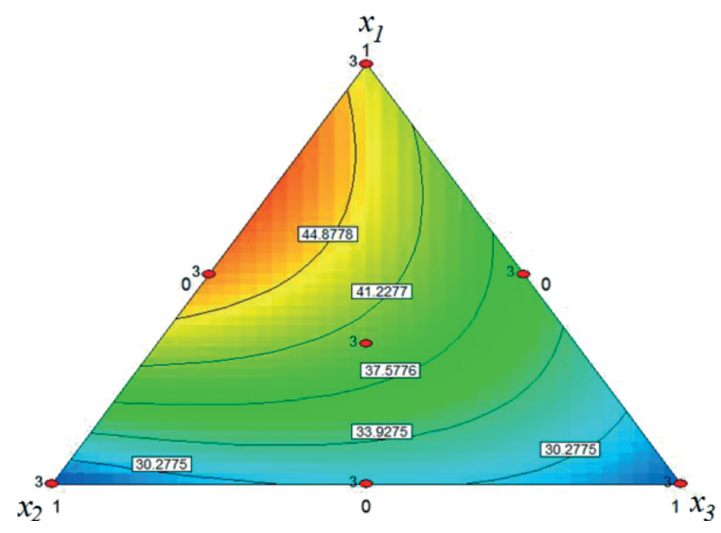

(b)

Figure 4. Response surface of the region of combination of variables $\mathrm{x}_{1}, \mathrm{x}_{2}$ and $\mathrm{x}_{3}$ obtained with Equations 2 and 3 for (a) degree of conversion, (b) Vickers hardness.

close to those of the optimal values of the proposed model, which validates the model.

\section{Conclusions}

An increase in hardness was observed in dental restorative resins containing hybrid polymer $\left(\mathrm{ORMOCER}{ }^{\circledR}\right)$, indicating a greater rigidity of these systems when they were compared to those of resins containing conventional monomers. The use of diluting monomers together with hybrid polymers improves the mechanical quality and handling of the formulations due to the decrease in the viscosity of ORMOCER ${ }^{\circledR}$. In addition, the mathematical model obtained was validated for prediction of the optimal resin composition to achieve higher values of DC and hardness.

\section{Acknowledgements}

The authors thank CNPQ (Process. 473279/2007-0) and Fundação Araucária (Project 385/12) for the financial support and Essthec Inc. (USA) for silica samples. Sandro A. S. Venter thanks UTFPR/Apucarana for the doctoral leave. 


\section{References}

1. Hass K and Wolter H. Synthesis, properties and applications of inorganic-organic copolymers (ORMOCER ${ }^{\circledR} \mathrm{S}$ ). Current Opinion in Solid State and Materials Science. 1999; 4:571-580. http://dx.doi.org/10.1016/S1359-0286(00)00009-7

2. José NM and Prado LASA. Materiais Híbridos OrgânicoInorgânicos: Preparação e Algumas Aplicações. Química Nova. 2005; 2:281-288. http://dx.doi.org/10.1590/S010040422005000200020

3. Cavalcante LM, Schneider LFJ, Hammad M, Watts DC and Silikas N. Degradation resistance of ormocer- and dimethacrylate-based matrices with different filler contents. Journal of Dentistry. 2012; 40:86-90. PMid:22079370. http:// dx.doi.org/10.1016/j.jdent.2011.10.012

4. Haas KH. Hybrid inorganic-organic polymers based on organically modified Si-alkoxides. Advanced Engineering Materials. 2000; 9:571-582. http://dx.doi.org/10.1002/15272648(200009)2:9<571::AID-ADEM571>3.0.CO;2-M

5. Manhart J, Kunzelmann K-H, Chen HY and Hickel R. Mechanical properties and wear behavior of light-cured packable composite resins. Dental Materials. 2000; 16:33-40. http://dx.doi.org/10.1016/S0109-5641(99)00082-2

6. Moszner N, Gianasmidis A, Klapdohr S, Fischer UK and Rheinberger V. Sol-gel materials 2. Light-curing dental composites based on ormocers of cross-linking alkoxysilane methacrylates and further nano-components. Dental Materials. 2008; 24:851-856. PMid:18045680. http://dx.doi. org/10.1016/j.dental.2007.10.004

7. Cramer NB, Stansbury JW and Bowman CN. Recent Advances and Developments in Composite Dental Restorative Materials. Journal of Dental Research. 2011; 90:402-416. PMid:20924063 PMCid:3144137. http://dx.doi.org/10.1177/0022034510381263

8. Ferracane JL. Resin-based composite performance: Are there some things we can't predict?. Dental Materials. 2013; 29:51-58. PMid:22809582. http://dx.doi.org/10.1016/j.dental.2012.06.013
9. Marghalani HY. Post-Irradiation Vickers Microhardness Development of Novel Resin Composites. Materials Research. 2010; 13:81-87. http://dx.doi.org/10.1590/S151614392010000100017

10. Lizymol PP. Effects of Diluent's Concentration upon the Properties of Organically Modified Ceramics Based Composites for Application in Dentistry. Journal of Applied Polymer Science. 2004; 94:469-473. http://dx.doi.org/10.1002/ app.20891

11. Sakka S and Kamiya K. The sol-gel transition in the hydrolysis of metal alkoxides in relation to the formation of glass fibers and films. Journal of Non-Crystalline Solids. 1982; 48:31-46. http://dx.doi.org/10.1016/0022-3093(82)90244-7

12. Pankow $\mathrm{O}$ and Naake-Schmidt G. Preparation and Characterization of Organic/Inorganic Polymer Composites Based on Mg-Silicates. Macromolecular Materials and Engineering. 2004; 289:990-996. http://dx.doi.org/10.1002/ mame. 200400141

13. Habsuda J, Simon GP, Cheng YB, Hewit DG, Lewis DA and Toh H. Organic-Inorganic hybrids derived from 2-hydroxyethylmethacrylate and (3-methacryloyloxypropyl) trimethoxysilane. Polymer. 2002; 43:4123-4136. http://dx.doi. org/10.1016/S0032-3861(02)00209-4

14. Nam K, Lee T, Bae B and Popall M. Condensation reaction of 3-(methacryloxypropyl)-trimethoxysilane and diisobutylsilanediol in non-hydrolytic sol-gel process. Journal of Sol-Gel Science and Technology. 2006; 39:255-260. http:// dx.doi.org/10.1007/s10971-006-7884-y

15. Elliot JE and Bowman CN. Kinetics of Primary Cyclization Reactions in Cross-Linked Polymers: An Analytical and Numerical Approach to Heterogeneity in Network Formation. Macromolecules. 1999; 32:8621-8628. http://dx.doi. org/10.1021/ma990797i 